\title{
Evaluation of E-Learning Readiness: A Study of Informational Behavior of University Students
}

\author{
Michael Brückner and Orasa Tetiwat
}

\begin{abstract}
In this study we investigated the behavior of university students from different universities and faculties of Thailand with regard to search, evaluate, use and share information. Our goal was to prepare the introduction of personal information management into the e-learning curriculum. We compare our results with data reported by others. Method: For gathering the data we used a questionnaire in Thai language, which was actually translated from the English original and sent to various universities in Thailand. Follow-up interviews with an adapted set of questions were carried out to generate qualitative data and a deeper insight into the knowledge and practices of the students. Analysis: Both quantitative and qualitative analyses were carried out on the data coming from 1,317 university students. Quantitative analysis employed the statistical package SPSS. Results: We have got a picture of the present informational behavior of Thai students. The results showed some differences between Thai and foreign students, for example in the use of Internet search engines. The insights gained by this study will be applied in the generation of the part of the e-learning curriculum that deals with the students' personal information management and can be applied to informational behavior of students in other countries like Mexico, Brazil, etc.
\end{abstract}

Index terms-Personal information management, Thailand, university students, e-learning curriculum.

\section{INTRODUCTION}

$\mathrm{T}_{\mathrm{t} \text { te }}^{\mathrm{H}}$ HE university system in Thailand began in 1917 with the establishment of the Chulalongkorn University in Bangkok. Today there are many different public and private universities in the country. The established universities in both the government and private sectors offer excellent programs especially in the fields of Medicine, the Arts, Humanities, and Information Technology, although many students prefer to pursue studies of law and business in Western faculties abroad or in those which have created local facilities in Thailand. For an overview of Thailand's educational system, refer to [1]. During the first years of the 21st century, the number of institutions called universities increased dramatically. As university students all over the world Thai students have to deal with the growing amount

Manuscript received April 25, 2009. Manuscript accepted for publication August 14, 2009.

The authors are with the Department of Computer Science, Faculty of Science, Naresuan University, Phitsanulok 65000, Thailand (e-mail: michaelb@nu.ac.th). of data, information and knowledge being created, evaluated, used and disseminated in many different forms, not at least in e-learning activities.

Thailand has set up a National ICT Education Master Plan recently, as stated in [2], aiming amongst others at integrating technological knowledge (i.e. ICT knowledge) and information management skills to develop the ability to analyze, think creatively, solve problems, and work in teams. This has led to a large number of distance learning activities and projects in the country.

E-learning in Thailand has been studied by Suanpang and Petocz [3] as a case study on a course in Business Statistics at Suan Dusit Rajabhat University with some 1,000 participants. They found that online courses can generate a more favorable learning outcome, for example significantly higher grades, than traditional courses. They explain this in part with the higher use of advanced technological support and diverse materials by online students for their learning than the traditional students had received. They also found that students in online courses assess themselves with a higher score than those in traditional courses.

Students participating in online courses have to know how to find, use, and share information for learning. Personal information management refers to both the practice and the study of human activities to gather, organize, store, retrieve and use information objects such as paper-based, digital and online documents, web pages and email messages for everyday use to complete job-related and other tasks. Since students have to deal with a huge amount of information, personal information management seems to be a necessary skill to achieve; this is especially useful for online courses.

There is not much literature available that deals with the behavior of Thai students using information and the Internet. Focusing on web page design Vitartas and Sangkamanee provided a study on Thai students' use of the Internet ([4]). They carried out a survey among 170 students of Assumption University in Bangkok with the help of a questionnaire. The authors concede that "the findings are limited to a sample size which may not provide adequate representation of all Thai University students".

In this study we want to show how prepared Thai university students are with regard to online education. For this, we investigated the personal information behavior of 
Thai university students with the help of paper-based, online and interview questionnaires to gain quantitative as well as qualitative data. The results of this study can be useful for setting up online or distance learning courses that use the Internet as a technological basis.

This paper is organized as follows. After the introduction we outline the research method of the questionnaires that led to the quantitative results presented and briefly discussed given in table form. After that, we introduce some of the results gained through the interviews. Finally, we draw conclusions and give some hints on further work related to this research.

\section{RESEARCH METHOD}

The methods used in this research were questionnaires and interviews to get quantitative as well as qualitative data for answering the research questions. A questionnaire is a research instrument consisting of a series of questions and other prompts for the purpose of gathering information from respondents. Although they are often designed for statistical analysis of the responses, this is not always the case. As a type of survey, questionnaires also have many of the same problems relating to question construction and wording that exist in other types of opinion polls.

The construction of a questionnaire needs careful consideration. As Peterson states, "the quality of the information obtained from a questionnaire is directly proportional to the quality of the questionnaire, which in turn is directly proportional to the quality of the question construction process” ([5]).

In this research we used a self-administered questionnaire approach for the quantitative aspects, which helped us to reach more people in the data gathering process. Additionally, we carried out a series of interviews with students from different faculties and years of study to set a basis for the qualitative data and using an adapted set of questions. Table I gives an overview of the number of open and closed questions used in this research.

TABLE I

OVERVIEW OF THE QUESTIONNAIRES USED IN THIS RESEARCH.

\begin{tabular}{cccc}
\hline Questionnaire & $\begin{array}{c}\text { No. of closed } \\
\text { questions }\end{array}$ & $\begin{array}{c}\text { No. of open } \\
\text { questions }\end{array}$ & Sum \\
\hline $\begin{array}{c}\text { Self-administered } \\
\text { questionnaire }\end{array}$ & 24 & 2 & 26 \\
$\begin{array}{c}\text { Questionnaire for } \\
\text { interviews }\end{array}$ & 13 & 10 & 23 \\
\hline
\end{tabular}

During a two-month period we piloted the questionnaire in Thai language and evaluated the results for comprehensibility and integrity. Possible ambiguities were removed by adapting the wording of the questions and translating them into English for the comparison group. The questionnaire was then sent out to different tertiary educational institutions in Thailand and in other countries to gather the data. From the returned answer sheets we discarded those that were filled out incorrectly, e.g. sheets with missing answers.

To measure the reliability of the questionnaire we used the split-half method. The split-half method is one of the methods used to assess reliability. With this method, the questionnaire is administered to a group of respondents and then the items are split in half, for example odds and evens, for purposes of scoring. The results of the two halves are then compared. The split-half method offers a clear advantage in terms of time and resources over the test-retest and the alternative form methods in that it does not require the test to be administered twice to the same group of respondents. In this case the results could be doubtful, because the respondents might remember their first answer and just repeat it or choose to answer the questions this time in the opposite way.

For a more detailed view on the questions for the followup interviews refer to section "Qualitative results from the interviews" and the Appendix below.

\section{QuAntitative Results FROM the PAPER-BASED AND ONLINE QUESTIONNAIRES}

In this section we present the main body of the most significant data collected through the paper-based and online questionnaires. The qualitative data extracted from the follow-up interviews are dealt with in the following section. In Table II the proportion of the male and female students is shown for each of the research instruments, i.e. the questionnaires and interviews.

TABLE II

SAMPLE SIZES OF PAPER-BASED/ONLINE AND FOLLOW-UP INTERVIEWS.

\begin{tabular}{crrr}
\hline Type & Male & Female & Totals \\
\hline Paper-based questionnaire & 250 & 452 & 702 \\
Online questionnaire & 336 & 256 & 592 \\
Interviews & 11 & 12 & 23 \\
Total & 597 & 720 & 1317 \\
Percentage & $45.3 \%$ & $54.7 \%$ & $100 \%$ \\
\hline
\end{tabular}

We used a paper-based and an online questionnaire to generate the data needed for the research.

In total there were 1,317 students that took part in this research compared to the total number of university students of 2,25 Mio ([6]), so the general level of accuracy of our data can be calculated as $2.7 \%$ for the confidence interval with a $95 \%$ confidence level. The number of respondents to the questionnaires also show a Gender Parity Index (GPI, the female-to-male ratio) of 1.20, which is similar compared to the actual GPI of enrolled students in tertiary educational institutions in Thailand, which has risen between 1998 and 2002 from 1.15 to 1.17 ([6]). 
The main body of data is about the students' habits related to information. The questions in the questionnaires and interviews covered the following topics for which the results are given in the tables below:

The main body of data is about the students' habits related to information. The questions in the questionnaires and interviews covered the following topics for which the results are given in the tables below:

- Recognizing information needs (Table III),

- $\quad$ Seeking for information (Table IV),

- Using search engines (Table V),

- Information sources being used (Table VI),

- Using and evaluating information (Table VII),

- Dissemination of information (Table VIII).

TABLE III

RECOGNIZING INFORMATION NEEDS.

\begin{tabular}{lr}
\hline \multicolumn{1}{c}{ Recognizing information needs } & Percentage \\
\hline I recognize information myself & 70.3 \\
My teacher tells me when I need & 24.1 \\
Others $\quad$ needs & 5.6 \\
\hline \multicolumn{1}{c}{ When noticing information } & Percentage \\
\hline Before an assignment & 16.9 \\
Before a test & 16.6 \\
For preparing class lectures & 13.8 \\
For doing research & 11.2 \\
For writing reports and papers & 23.1 \\
For entertainment & 16.8 \\
Others & 1.6 \\
\hline
\end{tabular}

information by themselves through the help of assignments, papers (reports) and tests they have to return to their teachers. The many reports Thai students typically have to prepare during the terms help them to understand information needs rather naturally. On the other hand, quite a few students seem to notice information needs mostly for entertainment (16.8\%).

In Table IV the main data for Thai students' information seeking behavior are summarized. These data were derived from a part of the questionnaire, in which we used the Likert scale ([7]). Whereas it is not surprising that the use of Internet search engines has become second nature to the students, their willingness to plan for their search is remarkably high. $53.7 \%$ of the students plans "always" or "mostly" for their information seeking task. The low rates for using library tools as valuable information sources have been already noticed by many librarians and have led to various initiatives to retain students in library activities. The Internet as a source for information outnumbers textbooks by far: $83.6 \%$ use the Internet "always" or "mostly", in parallel $61.6 \%$ use textbooks "always" or "mostly". We believe that this behavior together with the high planning rate mentioned above offers good chances for offering online courses successfully.

Since search engines are used extensively to get to informative web sites it is interesting to see which of them are actually used.

Table V shows the figures we have got for the use of major search engines. These figures differ surprisingly from those of the USA gained from Sullivan ([8]). Local Thai search portals, i.e. Sanook, Kapook and Hunsa, are in sum equally popular as Google, although Google is accessible via a convenient interface in Thai language. Not surprisingly, Sullivan does lack data for the locally oriented Thai search engines.

Table III is about recognizing information needs by the students. Because Thai universities are much more like a school, it is not surprising that students tend to recognize

TABLE IV

SEEKING FOR INFORMATION (IN PERCENT).

\begin{tabular}{lrrrrr}
\hline \multicolumn{1}{c}{ Question } & Always & Mostly & Sometimes & Seldom & Never \\
\hline $\begin{array}{l}\text { Do you plan for seeking information? } \\
\text { How often do you use the Internet for finding specific }\end{array}$ & 11.1 & 42.6 & 43.0 & 2.6 & 0.7 \\
$\begin{array}{l}\text { information? } \\
\text { Do you use Internet search engines for seeking }\end{array}$ & 44.3 & 39.3 & 16.0 & 0.3 & 0.1 \\
information? & 46.2 & 33.9 & 16.1 & 2.4 & 1.4 \\
How often do you use the online catalog of your library? & 5.5 & 16.0 & 42.7 & 21.4 & 14.4 \\
How often do you go to the library for seeking information? & 6.6 & 24.9 & 50.0 & 15.1 & 3.3 \\
Do you use textbooks for seeking information? & 15.5 & 46.1 & 32.8 & 4.6 & 1.0 \\
\hline
\end{tabular}


TABLE V

USE OF SEARCH ENGINES.

\begin{tabular}{lrr}
\hline \multirow{2}{*}{$\begin{array}{c}\text { Search } \\
\text { engine }\end{array}$} & \multicolumn{2}{c}{$\begin{array}{c}\text { Preferred usage in } \\
\text { \% }\end{array}$} \\
\cline { 2 - 3 } & Thailand & \multicolumn{1}{c}{ USA } \\
\hline Google & 37.7 & 49.2 \\
Sanook & 16.0 & - \\
Kapook & 13.1 & - \\
MSN & 12.6 & 9.6 \\
Yahoo & 10.1 & 23.8 \\
Hunsa & 6.4 & - \\
Altavista & 1.1 & - \\
Excite & 1.1 & - \\
Lycos & 0.3 & - \\
Others & 1.4 & 8.5 \\
\hline
\end{tabular}

In Table VII the students' use and evaluation of information is briefly shown. As expected there is a major tendency to copy and paste information from the Internet. More than $80 \%$ of the students seem to do this on a regular basis. On the other hand, students seem to be aware of possible inaccuracies of information found in the Internet and in other information sources. More than $70 \%$ check information before they use them. The students rank the reliability of the information sources as follows: textbooks (74.3\%), academic journals (67.5\%), Internet (53.4\%9, TV and radio (53.9\%), and newspapers (47.1\%).

TABLE VI

THAI STUDENTS' MAIN INFORMATION SOURCES.

\begin{tabular}{lr}
\hline \multicolumn{1}{c}{ Sources } & Percentage \\
\hline Online journals & 34.0 \\
Colleagues/peers & 24.7 \\
Paper journals & 22.6 \\
Supervisors & 13.1 \\
Librarians & 3.7 \\
Others & 1.8 \\
\hline
\end{tabular}

In Table VI the main sources of information for Thai students are presented. As can be seen clearly, online journals offer the most relevant source of information for the students, followed by human sources. Librarians seem to play a marginal role as a source of information.

TABLE VII

INFORMATION USAGE AND EVALUATION.

\begin{tabular}{lrrrrr}
\hline \multicolumn{1}{c}{ Question } & Always & Mostly & Sometimes & Seldom & Never \\
\hline Do you copy and paste information when you find it in the Internet? & 36.9 & 46.9 & 14.9 & 1.0 & 0.3 \\
Do you check information before you use it? & 24.3 & 46.6 & 25.3 & 3.4 & 0.3 \\
Do you think the information in textbooks is reliable? & 19.4 & 54.9 & 24.0 & 1.4 & 0.3 \\
Do you think the information in academic journals is reliable? & 14.8 & 52.7 & 32.0 & 0.3 & 0.3 \\
Do you think the information in the Internet is generally reliable? & 8.0 & 45.4 & 44.3 & 2.1 & 0.1 \\
Do you think the information in newspapers is reliable? & 7.0 & 40.1 & 48.6 & 4.0 & 0.3 \\
Do you think the information in TV and radio is reliable? & 9.6 & 44.3 & 42.8 & 3.0 & 0.3 \\
\hline
\end{tabular}

TABLE VIII

INFORMATION DISSEMINATION.

\begin{tabular}{lrrrrr}
\hline \multicolumn{1}{c}{ Questions } & $\begin{array}{c}\text { > 4 times a } \\
\text { year }\end{array}$ & $\begin{array}{c}\text { >2 times a } \\
\text { year }\end{array}$ & $\begin{array}{c}\text { > once in 2 } \\
\text { years }\end{array}$ & $\begin{array}{c}\text { once a } \\
\text { year }\end{array}$ & never \\
\hline How often do you publish papers in academic journals? & 2.7 & 9.0 & 10.7 & 10.1 & 67.5 \\
How often do you give talks about your work (on & 11.4 & 17.2 & 18.7 & 21.0 & 31.6 \\
conferences or in the labs)? & & & & & \\
How often do you publish web sites/blogs? & 16.5 & 17.2 & 18.2 & 20.5 & 27.5 \\
How often do you write articles for newspapers? & 2.6 & 6.2 & 6.4 & 7.7 & 77.1 \\
How often do you write reports? & 43.1 & 27.1 & 16.1 & 10.0 & 3.6 \\
How often do you make reportages for radio and TV? & 5.1 & 8.7 & 10.0 & 11.7 & 64.5 \\
\hline
\end{tabular}


In Table VIII the students' behavior related to the dissemination information is presented. Here we asked the students about the frequency by which they give talks, publish papers, turn in reports, upload to blogs or web sites.

The answers were standardized for each kind of dissemination, i.e. "never", "once a year", "more than once in 2 yrs", "more than twice a year" and "more than 4 times a year".

\section{QUALITATIVE RESULTS FROM THE INTERVIEWS}

In this section we present some of the qualitative results gathered by interviews with 23 students. The interviews lasted between 39 minutes and 77 minutes with an average duration of 61 minutes and were carried out in the university premises. During the interviews notes were taken according to the predefined questions handed over two or three days in advance to let the participants understand the questions and interview practice.

To obtain more detailed information we used structured interviews with 23 questions that were pre-determined and identical for every interviewee. The interviewer was a university lecturer with a background in computer science and information technology speaking Thai and English. We read out the questions and noted the answers without commenting them.

Because of the limited space we present in the following only some of the results that we find most interesting.

One of the questions was "Do you explore general information sources, such as encyclopedias, to become more familiar with a topic? Which sources do you use?" 20 out of 23 students actually use such sources, and they indicated that they benefit from online encyclopedias, e.g. Wikipedia. This is not surprising, since the Wikipedia project is well-known and has a Thai version available since the end of 2004. We later asked "Have you ever published valuable information in the Internet, such as writing articles for the Wikipedia (not social networks, Hi5)?" This question was answered positively by only one student. Compared with the questionnaire results presented above, which showed that more than $33 \%$ of the students publish web sites and blogs regularly, this might be seen as a contradiction. Here we asked for "valuable information" published by the student, so we would assume that a high number of students is active more on social networks, e.g. Hi5, which in fact is a popular element of Thai students' Internet life. This is clearly a point for further study.

The question "Do you know the difference between primary and secondary sources?" was not understood by all students. Since this question cannot be explained, otherwise the interviewer would have given the answer by himself, it works as an examination question about information management. Two students mixed primary and secondary with most important and less important, respectively. 16 students failed to answer at all, making up 5 students who knew the correct answer.
The question "How do you notice when you have enough information and when you need to get more? And if you need more, do you have processes and mechanisms for getting it (e.g., interlibrary loan; using resources at other locations; obtaining images, videos, text, or sound)?" is a complex one. It can be answered in different ways, e.g. in practical terms of a project and with respect to search strategies (precision and recall), and we were curious how the students would respond to it. The students' answers were quite pragmatic as the slight majority (13 students) stated that they stop searching when they feel time pressure to perform the following tasks, e.g. writing the main body of a report, but 8 of this pragmatic group of students return to the searching process if they feel a further need for information. 6 students related the problem to identify, whether or not they had enough information, to the production process during the project. They said if they had a source for every statement they made in their publication and at least another source for the main points they felt satisfied with the amount of information gathered for their work.

We asked the question "Are you comfortable citing different kinds of information?" and got the general impression that the students do not know enough about referencing methods and styles. None of the students answered positively, and from our experience of working with Thai students for some years we can confirm this result.

The questionnaire created for the interviews is presented in the appendix of this paper.

\section{CONCLUSIONS}

In this research we used questionnaires and interviews to gather data about the personal information habits of Thai students. We used quantitative and qualitative methods to analyze the results, which lead to new insights for setting up appropriate learning materials related to the students' personal information management.

From the data we see the need at least for

- Making the students more aware of the problems of copying and pasting materials in their academic texts without citing correctly, and

- Instructing common and appropriate citation methods for sources used in their materials.

All of this will be integrated into a new curriculum on "Methods of Research" introduced recently at the Faculty of Science at Naresuan University.

\section{FURTHER WORK}

This study focused mainly on the personal information behavior of Thai students. The comparison with the behavior of students from other countries and educational cultures is difficult because of the different focus groups and different questionnaires used. It is desirable to carry out a cross-cultural study preferably with a common questionnaire and similar focus groups to compare results for the personal information behavior of students in tertiary education. 
For a more thorough picture of the personal information management of students it would be desirable to include the use of appropriate tools into the research focus, for example electronic address books and instant message archiving.

Further work has also to be done to incorporate best practices and useful knowledge for personal information management into the curriculum. Moreover, it would be worthwhile to find out what kind of information Thai students contribute to the Internet, since there are a considerable number of them actually publishing.

\section{APPENDIX: COMPLETE QUESTIONNAIRE USED FOR THE INTERVIEWS (IN ENGLISH)}

1. Do you talk with instructors and participate in class or electronic discussions to identify a research topic, or any other information need?

2. Do you explore general information sources, such as encyclopedias, to become more familiar with a topic?

3. How do you work out a focus for a research question or a research paper that you can manage?

4. When you look at resources, how do you identify the purpose and audience of potential resources (e.g. popular vs. scholarly, current vs. historical)?

5. Do you know the difference between primary and secondary sources?

6. How do you notice that you have enough information or that you need more? And if you need more, do you have processes and mechanisms for getting it (e.g. asking peers, using resources at other locations, obtaining images, videos, text, or sound)?

7. When you use an information retrieval system, such as an online database, have you considered how it is organized and what is the best way to get information from it?

8. How do you search? Do you use key words, controlled vocabulary, Boolean operators, proximity searching, and truncation?

9. Do you use different formats of information? How do you get it?

10. Do you use different resources to get information (e.g. Internet, local and national library, professional associations, institutional research offices, experts and practitioners)?

11. When you cannot find information, what do you do? Do you take a different approach and try again, refine your strategy? Refocus? Figure out ways to fill in gaps? Do it all again?

12. Do you consider yourself a computer-literate person? Do you know how to use computer functions reasonably well? How about other technologies?

13. How do you organize the information you use? Folders for subjects/topics? Chronological order?

\section{Are you comfortable citing different kinds of information?}

15. How do you pick out the important parts of what you find and read in order to find the parts useful for you? How do you decide when to paraphrase things and when to quote things - do you have any rule of thumb?

16. Do you evaluate information that you want to use? Which criteria do you use? Do you look for bias, prejudice?
17. Do you ever question the accuracy of the information you have found? Ever compare information from different sources to see whether one makes more sense than the other?

18. Have you ever tried to contact an "expert" to validate information you are finding?

19. Do you provide outlines when you are writing something organize the information you are using in some way?

20. In doing a paper or a project - have you ever kept a journal or log of activities about how you got or evaluated information and then written up what you found?

21. Have you ever considered that a written report is not the best way to convey information - that video or something else might provide a better way to convey information?

22. Have you given any thought to privacy and security issues in the electronic environment?

23. How about plagiarism - are you confident that you know enough to avoid it?

24. Have you ever published valuable information in the Internet, such as writing articles for the Wikipedia (but not social networks and Hi5)?

\section{REFERENCES}

[1] S. Pitiyanuwat, S. and S. Sujiva, "Civic Education in Thailand. Policies and practices in schools," Bangkok: Chulalongkorn University Press 2005.

[2] D. Ainley, P. Arthur, P. Macklin and B. Rigby, "Thai Learning Technologies 2010. Capacity building of Thai education reform (CABTER) Stage 1 - Learning technologies,” 2003. Available: http://www.onec.go.th/publication/a_tech/a_tech.pdf (last accessed October 16, 2008).

[3] P. Suanpang and P. Petocz, "E-Learning in Thailand: An Analysis and Case Study". International Journal on E-Learning, Chesapeake, VA: AACE, vol. 5, no. 3, pp. 415-438. 2006.

[4] P. Vivartas and S. Sangkamanee, "Profiling Thai students' use of the Internet: implications for Web page design," in ACSILITE Conference, Southern Cross University, Coos Harbour, Australia, 9-14 Dec 2000. Available:

http://www.ascilite.org.au/conferences/coffs00/papers/peter_vitartas.pdf (last accessed October 14, 2008).

[5] R. A. Peterson, "Constructing effective questionnaires," London: Sage 2000.

[6] "UNESCO, Global Education Digest 2005. Comparing Education Statistics across the World,” Montreal: UNESCO Institute for Statistics 2005. Available:

http://www.uis.unesco.org/template/pdf/ged/2005/ged2005_en.pdf (last accessed October 13, 2008).

[7] R. Likert, "A technique for the measurement of attitudes," Archives of Psychology, vol. 140, no. 1, pp. 1-55, 1932.

[8] D. Sullivan, "Nielsen net ratings search engine ratings," 2006. Available online at http://searchenginewatch.com/showPage.html?page=2156451 (last accessed Oct. 14, 2008). 